\section{A Comunicação Política depois do Golpe - Notas para uma agenda de pesquisa}

\author{
[Political Communication after \\ the Coup - Notes for a \\ Research Agenda]
}

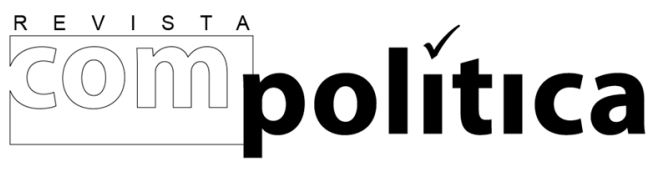

revista compolítica 2018, vol. 8(2)

compolitica.org/revista

ISSN: 2236-4781

DOI: 10.21878/compolitica.2018.8.2.193

O. Open Access Journal

\author{
Afonso Albuquerque \\ Universidade Federal Fluminense \\ [Fluminense Federal University]
}

\begin{abstract}
Resumo
O golpe jurídico-parlamentar de 2016 pegou de surpresa os pesquisadores brasileiros em Comunicação Política. Como e por que isso pôde acontecer? Este artigo sustenta que o problema se deve à incapacidade da pesquisa brasileira em definir a própria agenda de investigação. Por um lado, o Brasil se constitui como um país periférico no cenário internacional da pesquisa, e essa condição torna os pesquisadores brasileiros particularmente propensos a reproduzir, de maneira pouco crítica, premissas e modelos cunhados para dar conta de condições inteiramente diferentes das que se apresentam no seu país. Pelo outro, um conjunto diversificado de atores tem, ativa e sistematicamente, emprestado caráter de verdade científica a agendas acadêmicas politicamente orientadas.
\end{abstract}

Palavras-chave: comunicação política, golpe 2016, Brasil.

\begin{abstract}
The parliamentary coup of 2016, which ousted President Dilma Rousseff, took by surprise Brazilian Political Communication researchers. Why and how this could happen? This paper argued that this problem is due to the relative inability of Brazilian researchers to define the research agenda itself. This occurs for two reasons. On the one hand, Brazil occupies a peripheral position in the global research landscape, and therefore Brazilian researchers tend to reproduce foreign perspectives without the criticism models and premises coined for describing circumstances entirely different from those existing in Brazil. On the other hand, since the end of the World War II, a variegated group of actors have presented politically oriented agendas as having scientific validity.
\end{abstract}

Keywords: political communication, 2016 Coup, Brazil. 


\section{A Comunicação Política depois do Golpe - Notas para uma agenda de pesquisa}

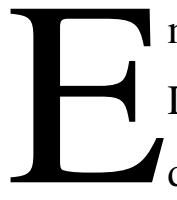

m 31 de agosto de 2016, um golpe parlamentar pôs fim ao governo da presidente Dilma Rousseff, do Partido dos Trabalhadores (PT). A votação do impeachment de Rousseff pelo Senado foi o desenlace de um longo processo de desgaste e deslegitimação do Governo Federal e das lideranças políticas do PT, ou a ele associadas, no qual setores do Judiciário, do Ministério Público, da Polícia Federal e, ainda mais importante, da mídia tradicional desempenharam um papel fundamental, cujo marco inicial remete para o processo judicial do Mensalão ${ }^{1}$, e que se prolongou em um novo processo judicial, a Operação Lava Jato².

Uma vez empossado, o novo governo liderado pelo vice-presidente Michel Temer pôs em marcha uma política de ataque aos direitos sociais, e o Judiciário e a imprensa permaneceram à frente de uma campanha sistemática que objetiva a criminalização do PT e de suas lideranças, visando impedir a candidatura do ex-presidente Luiz Inácio Lula da Silva à Presidência em 2018. Tomados em conjunto, esses acontecimentos parecem sugerir um processo de crescente autonomização das instituições representativas em relação ao princípio da vontade popular, expressa pelo voto e, em contrapartida, um papel cada vez mais ativo na política por parte das instituições de accountability, que deveriam atuar como elementos de sustentação do regime democrático. Longe de cumprir esse papel, as evidências sugerem que tais instituições têm sistematicamente sabotado a democracia e construído as bases para um sistema de características oligárquicas, ainda que formalmente democrático.

\footnotetext{
${ }^{1} \mathrm{O}$ Mensalão se refere a um escândalo de compra de votos parlamentares para formar uma base de apoio para o governo Lula. O escândalo estourou em 2005 e foi julgado em 2012. Diversos parlamentares foram condenados. O escândalo teve impacto significativo na percepção pública do PT que, desde então passou a ser sistematicamente associado, pela imprensa, com a corrupção.

${ }^{2}$ A Operação Lava Jato agrupa uma série de investigações conduzidas pela Polícia Federal desde 2014, que resultaram na prisão de vários líderes políticos, dentre os quais Lula.
} 
Diante de transformações tão dramáticas no panorama político, cabe questionar: que contribuições a pesquisa em Comunicação Política no país tem oferecido para dar conta delas? Surpreendentemente, a resposta parece ser: muito pouco ou quase nada. Um vislumbre da publicação recente e das apresentações de trabalhos em eventos acadêmicos revela uma escassez de trabalhos que considerem a atuação da imprensa ou de outras instituições da "rede de accountability" sob uma perspectiva crítica - em contraste com aqueles que apresentam as instituições de accountability sob uma perspectiva positiva (ao menos potencialmente), tendo em vista iniciativas de e-democracia, e-participação ou etransparência. As perguntas que se seguem são: em que medida essa agenda continua a fazer sentido quando a democracia enfrenta uma crise tão séria? É sensato esperar que uma e-democracia possa existir na ausência da democracia propriamente dita?

Duas questões principais norteiam esse artigo: por que a pesquisa em Comunicação Política brasileira se demonstrou tão pouco eficaz em refletir sobre o processo de deterioração da democracia brasileira, que levou ao golpe de 2016, e por que, uma vez concretizado o golpe, ela tem demonstrado tão pouco apetite para investigá-lo? A hipótese que se trata de explorar é que os pesquisadores brasileiros apresentam pouca disposição em estabelecer os termos fundamentais que definem a agenda da sua investigação, e que isso se relaciona com três fatores mais gerais: 1) a posição periférica que o país ocupa no sistema internacional de pesquisa acadêmica, que o leva a desempenhar o papel de importador de perspectivas teóricas estrangeiras, tratando quando muito de adaptá-las à realidade nacional (Connell, 2012, Schwartz, 1977); 2) a reestruturação do sistema acadêmico, a partir de uma lógica da produtividade acadêmica organizada com base em um sistema de ranking global, cujos critérios se revelaram amplamente favoráveis à disseminação de perspectivas americanas e britânicas; 3) a crescente influência que instituições extra-acadêmicas organizações filantrópicas (fundações), Organizações Não-Governamentais (ONGs), think tanks, instituições financeiras internacionais, com destaque para o Banco Mundial e, não menos importante, o governo americano - têm exercido sobre a agenda acadêmica desde a década de 1950, mas de maneira mais acelerada, após o colapso da União Soviética e a construção de uma ordem internacional unipolar liderada pelos Estados Unidos.

Em particular, é digno de nota como, ao longo das últimas décadas, a literatura internacional progressivamente passou a endossar uma concepção instrumental da 
democracia. De modo crescente, isso a desvincula da ideia de que a vontade popular expressa nas urnas constitui o fundamento normativo que assegura a legitimidade do governo representativo e, cada vez mais, a relaciona a uma concepção essencialmente técnica - na qual ela é associada a mecanismos de controle de qualidade, agrupados em torno da categoria de accountability - e neoliberal - na medida em que grande parte da responsabilidade pela qualidade da democracia é delegada a agentes privados - da democracia.

Visto que a agenda da investigação acadêmica usualmente toma como dada a noção de que as instâncias de accountability contribuem para o aperfeiçoamento da democracia, a possibilidade de que elas viessem a, de modo articulado, agir no sentido de desestabilizar a ordem democrática passou desapercebida aos olhos dos pesquisadores. O ponto a se destacar é que o modelo de "democracia sem povo", que preserva o funcionamento das instituições representativas dentro de limites estritos - fazendo uso da perseguição judicial e midiática de figuras indesejáveis, como meio para impedir os desvarios da vontade popular - se beneficia da sua proximidade com alguns princípios fundamentais da literatura acadêmica sobre a accountability, embora, evidentemente, faça um uso depravado deles. Por esse motivo, argumentamos que o golpe de 2016 indica a necessidade de uma ampla revisão da agenda da pesquisa no campo da Comunicação Política no Brasil.

\section{O golpe de 2016 e suas lições}

O golpe que levou à queda da presidente Dilma em agosto de 2016 colocou em xeque a premissa acadêmica de que a democracia brasileira estava plenamente satisfeita sob um arranjo institucional sólido garantido na Constituição de 1988. O desenrolar do golpe deixou óbvio que a literatura da área, ao exagerar o enfoque positivo e crucial das instituições de controle (também chamadas de instituições de accountability) para a democracia representativa, não foi capaz de vislumbrar a falsa segurança do regime assentado nessas condições. Nesta seção inicial, descrevemos brevemente o processo que culminou no golpe ao governo da presidente Dilma. Discutimos a necessidade em revisar 
certa perspectiva institucional da política, argumentamos que instituições de controle não eleitas pelo voto foram centrais para a efetivação do golpe.

\section{O golpe de 2016}

No dia 17 de abril de 2016, por 367 votos favoráveis e 137 contrários, a Câmara dos Deputados aprovou o encaminhamento, para o Senado Federal, do processo de impeachment da presidente eleita Dilma Rousseff, por suposto crime de responsabilidade fiscal. O afastamento provisório da presidente que se seguiu a esta aprovação se tornou definitivo em 31 de agosto de 2016, quando o Senado aprovou o impeachment por 61 votos a 20. As origens do processo são, contudo, mais antigas. Elas remetem, em última análise, à recusa do candidato Aécio Neves (PSDB) em aceitar a derrota, no segundo turno das eleições presidenciais de 2014, com uma diferença de aproximadamente 3,3\% dos votos válidos. Logo após a divulgação dos resultados, Aécio começou uma constante campanha contra o mandato da então presidente, sendo um dos primeiros a colocar em pauta o tema do impeachment, antes mesmo de protocolarem as chamadas "pedaladas fiscais" cometidas por Dilma. O processo foi finalmente aberto no dia 2 de dezembro de 2015, pelo então presidente da Câmara, ex-deputado Eduardo Cunha (PMDB), atualmente preso e cassado por quebra de decoro parlamentar.

A Ciência Política tem nomeado o processo de "golpe parlamentar" (Santos, 2017), modelo ainda pouco usual nas democracias contemporâneas, mas que apresenta características em comum com um modelo de golpismo experimentado também pelo Paraguai e por Honduras (Pitts et al., 2016), no qual a aparência de normalidade das instituições políticas é mantida, ao mesmo tempo em que se recorre a brechas constitucionais para derrubar mandatários eleitos pelo voto popular. Ou seja, o processo adquire um verniz público legítimo na medida em que tudo se passaria "dentro da lei".

Essa concepção apreende muitos aspectos importantes da questão, mas, ao mesmo tempo, deixa de considerar outras variáveis relevantes. Em especial, o golpe não teria sido possível sem a participação ativa de um conjunto de instituições - o Judiciário, o Ministério Público, a Polícia Federal e a imprensa - que agindo na mesma direção, e de maneira colaborativa, 
viabilizaram o golpe, tendo como álibi o combate à corrupção (Albuquerque, 2017). Em particular, sustentamos que, na medida em que esses agentes não-eleitos assumem um papel de crescente protagonismo na vida política, a autoridade dos representantes eleitos e das instituições representativas declina. O fim abrupto do mandato da presidente eleita Dilma Rousseff ilustra, pois, de modo particularmente dramático, uma dinâmica na qual a lógica da accountability se volta diretamente contra a democracia. Dois aspectos em particular merecem atenção pelo impacto que tiveram no processo do golpe: a judicialização da política e o papel da imprensa na desestabilização da democracia.

\section{A judicialização da política}

Em linhas gerais, podemos identificar duas ordens de fatores - nacionais e internacionais - por detrás do desenvolvimento da judicialização da política no Brasil. A dimensão nacional do fenômeno tem sido objeto de uma ampla literatura (Avritzer \& Marona, 2017; Engelmann, 2016; Vianna, Burgos \& Salles, 2007), que identifica as origens do fenômeno nos arranjos estabelecidos pela Constituição de 1988. Em linhas gerais, esses arranjos estabeleciam medidas destinadas a garantir um grau considerável de independência do Poder Judiciário frente ao Executivo. O objetivo fundamental por trás dessas medidas era evitar a concentração do poder no Executivo, configurando o que O’Donnell (1991) denominou democracia delegativa, por meio da multiplicação de mecanismos de accountability horizontal, realizados por instituições de controle, paralelamente à accountability vertical realizada por meio de eleições livres e justas (O’Donnell. 1998). Contudo, mais do que simplesmente fortalecer as instâncias de controle sobre o Executivo, o efeito concreto dessas medidas foi promover um processo de concentração de poder nas mãos do aparato judicial constituído pelo Judiciário, o Ministério Público e a Política Federal (Arantes, 2010; Avritzer \& Marona, 2017; Vianna, Burgos \& Salles, 2007). Em particular, o Ministério Público passou a reivindicar para si um papel de guardião dos direitos da sociedade e, como tal, agente da cidadania (Arantes, 1999).

Os fatores internacionais se relacionam com o processo de ascensão e queda do Welfare State. Por um lado, o esforço de construção de um "capitalismo organizado" envolveu um processo de crescente regulamentação de diferentes aspectos da vida social, no qual o 
Judiciário assumia um papel essencial (Vianna, Burgos \& Salles, 2007). Por outro, dada a centralidade da posição assumida pelo Judiciário na sociedade, não é de se espantar que ele tenha sido um dos elementos fundamentais do processo de desmontagem do Welfare State e de sua substituição pela lógica do neoliberalismo. Cabe destacar, a esse respeito, a importância que o conceito de Rule of Law veio assumir a partir da década de 1990, sob o patrocínio do Banco Mundial, o Fundo Monetário Internacional (FMI) e outras instituições financeiras internacionais de âmbito regional (Santiso, 2004), bem como por governos ocidentais - e especialmente o governo americano que através de sua Agência para o Desenvolvimento Internacional e os Departamentos de Estado e de Comércio - se empenharam ativamente em promover reformas no sistema legal de países da Europa Oriental e antiga União Soviética, e também na Ásia e na América Latina a título de "ajuda legal" (Carothers, 1998).

Em conformidade com os princípios neoliberais, a Rule of Law consiste em "uma ordem legal que consiste de regras previsíveis, praticáveis e eficientes, necessária para que a economia de mercado possa florescer" (Santos, 2006: 253) e pressupõe a existência de um Judiciário independente, “capaz de tornar os detentores de poder accountable em relação às regras do jogo" (Gloppen, Gargarella \& Skaar, 2004). Sua lógica é, portanto, fundamentalmente distinta da Rule of Democracy, estruturada com base na consulta popular (Ferejohn \& Pasquino, 2003).

O processo de judicialização da política ganhou um impulso particularmente notável durante o período em que presidentes filiados ao PT estiveram à frente da Presidência, associado a processos de combate à corrupção, que tiveram na Ação Penal 470 (mais conhecida como o caso do Mensalão), iniciada em 2005, e, mais recentemente, na Operação Lava Jato. Como vários autores observaram, essas ações radicalizaram um padrão de intervenção das instituições do campo judicial sobre a esfera da representação política que é fundamentalmente hostil à democracia (Engelmann, 2016; Santos, 2017), ao qual Avritzer (2017) se referiu como pretorianismo judicial. O problema se agrava quando se considera o elemento de politização da Justiça que caracterizou intensamente tanto o processo do Mensalão quanto a Operação Lava Jato. Esta última, em particular, caracterizou-se por excessos, na forma como foi exercida, e um indisfarçável viés político no seu conteúdo. Santos (2017: 159) apresenta evidências de como, ainda em 2014, a Ação 
Penal 470 (popularmente conhecida como o caso do Mensalão), "estreou ostensivo espetáculo de intervenção jurídica na ordem política”, em que o objetivo maior era minar por via não eleitoral a liderança do PT. O autor relata em detalhes o uso de brechas constitucionais ao longo da Ação, em que, sem provas, os ministros, nas palavras do próprio então ministro Joaquim Barbosa afirmou em entrevista que a Constituição era aquilo que o Supremo Tribunal Federal diz que ela é (Santos, 2017, p.168).

\section{Imprensa e desestabilização da democracia}

Diferentemente do que acontece com o Judiciário, o papel da imprensa no processo de desestabilização da democracia brasileira tem sido relativamente pouco explorado (para algumas exceções ver Albuquerque, 2017; Azevedo, 2017; Van Dijk, 2017). Por certo, alguns textos têm discutido aspectos do comportamento da imprensa durante o processo de impeachment de Dilma Rousseff (exemplos incluem Becker, Cesar, Gallas \& Weber, 2017; Marques, Mont'Alverne \& Mitozo, 2017; Rizotto, Prudêncio \& Sampaio, 2017), sem, contudo, enfatizar as implicações que isso teve do ponto de vista da estabilidade da democracia.

O ponto a se destacar é que o impacto do Judiciário no processo golpista não teria sido o mesmo sem a ampla publicidade que os meios de comunicação ofereceram às suas ações, que ajudaram a sustentar a ideia de que o governo eleito era irremediavelmente corrupto. Dois exemplos expressivos disso foram a quebra do sigilo de conversas pessoais do expresidente Luis Inácio Lula da Silva, em março de 2016 (inclusive com a então presidente Dilma Rousseff), cujos áudios foram vazados seletivamente para a imprensa, interferindo assim no processo de impeachment que seria votado pelo Congresso um mês depois; e a condução coercitiva de Lula, expedida pelo juiz Sérgio Moro e executada pela Polícia Federal, também em março, na véspera da votação de impedimento de Dilma. Apesar do aceite do ex-presidente em depor, houve uso da coerção, transformando o ato em grande festa pela cobertura da imprensa.

Para além disso, desde 2005, mas com maior intensidade a partir de 2014, a grande imprensa atuou sistematicamente no sentido de deslegitimar os governos petistas, através 
da sua associação à corrupção e da sugestão de que eles estariam por trás de um projeto proto-autoritário de perpetuação no poder do Partido dos Trabalhadores. A importância do papel político da imprensa não passou desapercebida dos estudiosos da Comunicação Política, naturalmente, mas mesmo eles não parecem ter sido capazes de estimar o potencial corrosivo que ela poderia ter em relação à democracia de modo mais geral.

É certo que a literatura acadêmica nunca foi particularmente positiva sobre a performance democrática da imprensa brasileira. Aspectos como a concentração dos meios de comunicação nas mãos de umas poucas famílias poderosas, a ausência de uma estrutura de regulamentação das mídias capaz de conter abusos, o passado comprometedor de relações promíscuas dos meios de comunicação com o regime militar e a cobertura enviesada da política têm sido destacados inúmeras vezes, e apontados como fatores que afastam a imprensa de um papel construtivo em relação à democracia.

O que o golpe de 2016 ilustrou, contudo, foi algo muito diferente: os meios de comunicação ativamente conspiraram para esvaziar a legitimidade não apenas dos governantes eleitos particularmente os presidentes petistas entre 2013 e 2016 - mas do próprio princípio do voto popular como base da autoridade política, caracterizando-o como tendo uma natureza populista e fundamentada na ignorância. Em oposição a ele, a imprensa reivindicou para si o papel de porta-voz da opinião pública esclarecida, cuja responsabilidade inclui atenuar ou corrigir o resultado de más decisões populares.

À medida que os governos petistas insistiam em se perpetuar pelas urnas, a despeito da sua oposição sistemática, a grande imprensa se tornou cada vez mais propensa a encampar soluções menos ortodoxas, e ajudou a dar sustentação a um crescente movimento de criminalização da política, através de uma retórica que sistematicamente associava os líderes políticos - especialmente aqueles pertencentes ao PT e seus aliados - ao fenômeno da corrupção. Ao fazê-lo, ela ajudou a legitimar um processo de crescente intervenção do Judiciário na dinâmica política, que acabou por inviabilizar o segundo governo de Dilma Rousseff e, em última análise, ajudou a criar as condições que contribuíram com a viabilidade do golpe em 2016. 


\section{A Instituição do Modelo da Accountability na Agenda Acadêmica}

A ênfase que boa parte da literatura em Ciência Política (e da Comunicação Política, em especial) deposita na variável eficiência das instituições centrais da vida política, e no problema da sua accountability - em detrimento de outros fatores - na sua definição da democracia, deve ser entendida em referência a um conjunto de transformações mais amplas, relativas aos fatores institucionais externos afetam a agenda da pesquisa acadêmica. A rigor podemos identificar de duas formas distintas como essa lógica influenciou o meio acadêmico: a primeira teve suas origens antes mesmo da Segunda Guerra Mundial e dá conta da influência que as chamadas "agências filantrópicas" exerceram na conformação do campo da pesquisa na Comunicação e na Ciência Política nos Estados Unidos e no mundo, de maneira articulada com o Departamento de Estado desse país, no contexto da Guerra Fria; a segunda se refere à influência que um conjunto de agentes associados ao projeto de globalização neoliberal, capitaneado pelo Banco Mundial, em associação outras Instituições Financeiras Internacionais (IFIs), ONGs, think tanks e, mais uma vez, agências do governo dos Estados Unidos.

O modelo clássico: as instituições filantrópicas e a agenda da investigação nas ciências humanas

A influência exercida pelas instituições filantrópicas (fundações) na conformação de disciplinas das Ciências Humanas nos Estados Unidos é um processo muito bem documentado por diversos pesquisadores. Desde o final do século XIX, as fundações têm desempenhado um papel de destaque como agentes de reforma social e fomento à educação e pesquisa nos Estados Unidos (Walters \& Bowman, 2010). As Fundações Sage e Laura Spelmann tiveram um papel crucial no desenvolvimento do ensino das Ciências Sociais no país, nas décadas de 1910 e 1920 (Khurana, Kimura \& Fourcade, 2010); a Fundação Rockefeller teve um papel central na constituição da Comunicação como campo de pesquisa, no final da década de 1930, em meio a uma preocupação generalizada com a vulnerabilidade à propaganda estrangeira, na antevéspera da Segunda Guerra Mundial (Gary, 1996); e a Fundação Ford influenciou decisivamente a virada behaviorista da 
Ciência Política americana (Seybold, 1980) e o advento das business schools (Khurana, Kimura \& Fourcade, 2011). As fundações foram igualmente importantes em sua atuação internacional, permitindo aos Estados Unidos construírem uma relação hegemônica com os países da Europa Ocidental no campo científico, depois da devastação da Segunda Guerra Mundial (Krige, 2006) e, claro, tiveram um papel central no desenvolvimento das ciências sociais e econômicas no Brasil.

Embora a influência da Fundação Ford no desenvolvimento das ciências sociais brasileiras tenha sido frequentemente descrita com tons róseos, como um agente fundamentalmente progressista (cf. Miceli, 1993), na prática, a sua atuação foi muito mais ambígua. Tal como ocorreu com outras fundações, a Fundação Ford operou ativamente como um agente de influência dos Estados Unidos em escala global, no contexto da Guerra Fria e depois (McCarthy, 1987), contribuindo para dar valor universal a perspectivas associadas aos interesses estratégicos do país (Bourdieu \& Wacquant, 1999). De modo especial, a influência americana sobre a agenda da investigação internacional se caracterizou pela difusão do paradigma da modernização, que estabelecia a sociedade americana como um paradigma para as demais sociedades (Lerner, 1958). O impacto dessa lógica sobre a pesquisa na Ciência Política e na Comunicação não foi pequeno, como veremos a seguir.

\section{Ciência Política}

Não é exagero dizer que a moderna Ciência Política americana se desenvolveu sob as asas da Fundação Ford. Como bem o demonstrou Seybold (1987), mais do que simplesmente prover recursos financeiros, a Fundação Ford exerceu um papel intelectual e de organização ativo para o que se tornou conhecido como "revolução comportamental" (behavioral revolution) na ciência política. Até a Segunda Guerra Mundial, o debate americano no campo era dominado por análises formais sobre a natureza do governo e reflexões de cunho ético e moral sobre a política. No início da década de 1960, o paradigma behaviorista já ocupava uma posição hegemônica na Ciência Política americana. Isso só foi possível por conta do empenho sistemático da Fundação Ford, por meio da sua Behavioral Science Division, de treinar e favorecer a inserção acadêmica de pesquisadores comprometidos com esse estilo de trabalho, com um investimento massivo de 23 milhões 
de dólares - hoje isso corresponderia a cerca de dez vezes esse valor - numa época em que o governo americano não investia nas ciências sociais.

Os números mostram bem o impacto que essa iniciativa obteve, quando se considera que, dos 984 pesquisadores que participaram do projeto, 550 obtiveram vagas como professores universitários em 181 estabelecimentos de ensino superior; 29 desses estabelecimentos contrataram cinco ou mais dos egressos do programa e dez contrataram dez ou mais. Um grupo de pesquisadores da Columbia University, que incluía Seymour Martin Lipset, Richard Hofstadter, dentre outros, desempenhou um papel central na concepção do projeto, e autores como Robert Dahl, Richard Fenno e Philip Converse estiveram entre seus beneficiários.

Para além do elemento de homogeneização teórica e metodológica inerente, o sistema de formação e networking da Fundação Ford ajudou a legitimar cientificamente um conjunto de concepções políticas particulares, que patrocinavam uma concepção essencialmente técnica do governo e da política que, em sua versão mais extrema, considerava a participação popular como um elemento secundário da democracia - Dahl (1997) cunhou o termo "poliarquia" para denominar essa concepção particular de democracia na qual o povo é um elemento secundário. Lipset (1960) apresentou uma das versões mais extremas desse argumento, ao caracterizar a ampla participação popular como uma ameaça à continuidade do regime democrático - para ele, tudo depende de quem participa do processo político - de tal modo que ele toma a apatia política como uma virtude, e não um problema para a democracia.

\section{Comunicação}

A influência de agendas politicamente orientadas originadas nos Estados Unidos é ainda mais perceptível no caso da pesquisa em Comunicação. Estruturada como uma disciplina instrumental, na lógica das ciências sociais aplicadas, a pesquisa em Comunicação foi amplamente associada a duas agendas em particular: a comunicação para o desenvolvimento e a defesa da liberdade de imprensa. Não obstante tenham sido objeto de múltiplos questionamentos, ambas as agendas continuam a influenciar decisivamente a 
pesquisa de comunicação ainda hoje. Isso não acontece porque elas têm alicerces conceituais particularmente sólidos. Ao contrário, as obras que serviram de referencial para elas - Four Theories of the Press (Siebert, Peterson, \& Schramm, 1963) e Passing Traditional Society (Lerrner, 1958) - se caracterizam por sua notável fragilidade teórica, o que não impediu que elas tivessem uma extraordinária influência (Nerone, 1995; Rogers, 1976).

A influência dessas obras e da agenda a elas relacionada tem a ver, antes, com um intenso esforço de networking ligando determinadas universidades - com destaque para o departamento de Comunicação da Michigan State University - e agências do governo americano, bem como instituições internacionais, como a UNESCO (Rogers, 1976; 2001). Duas consequências derivam daí. Por um lado, essas circunstâncias tornaram possível aos Estados Unidos desfrutarem de uma posição amplamente hegemônica no campo internacional da pesquisa em comunicação, que se reflete em sua posição absolutamente dominante no tocante à produção científica em veículos de prestígio e nas posições de destaque das associações científicas internacionais (Lauf, 2005; Wiedemann \& Meyen, 2016). Por outro lado, elas contribuíram para a construção de boa parte do campo em bases intelectualmente muito frágeis, com características semi-acadêmicas e semi-profissionais e ausência de fundamentos conceituais sólidos na sua base (Peters, 1986).

De fato, o debate internacional sobre a comunicação tem, com enorme frequência, tomado como premissa a ideia da exemplaridade de modelos americanos, e do modelo do jornalismo "independente" de modo particular. Com base nela, o jornalismo das sociedades não ocidentais é invariavelmente avaliado tendo por referência aquele praticado nos Estados Unidos - por vezes o modelo britânico de radiodifusão pública (BBC) também serve de termo de comparação. Em linhas gerais, esses estudos consideram dois tipos básicos de situações: 1) casos em que essas sociedades adotam práticas que se aproximam do modelo americano - e nesse caso isso indica um processo de democratização/modernização (Boas, 2013; Lawson, 2002); 2) casos em que isso não acontece, e então a questão que se trata de explicar é que tipos de obstáculos impedem ou atravancam a modernização e a democratização da mídia (Hughes \& Lawson, 2005). Dessa forma, perdem-se de vista os elementos mais distintivos que caracterizam a organização dos meios de comunicação nessas sociedades (Albuquerque, 2005). 


\section{Neoliberalismo, Capitalismo Acadêmico e o Sistema de Rankings}

A partir do final do século passado, o colapso da União Soviética e dos regimes a ela associados e a emergência de uma nova ordem global, estruturada com base em princípios neoliberais, impactaram profundamente na lógica da produção acadêmica, de modo geral, e na agenda da pesquisa em Comunicação Política, em particular.

Nesse novo arranjo, as universidades passariam a ser avaliadas com base em critérios de eficiência análogos ao mercado - o que se tornou conhecido como capitalismo acadêmico (Paasi, 2005; Slaughter \& Leslie, 2001). Tal fato ganhou alcance global através de um mecanismo de classificação de universidades e unidades de ensino com base em sistemas de rankings (Amsler \& Bolsmann, 2012; Marginson \& van der Wende, 2007), cujos critérios favorecem desproporcionalmente pesquisadores e instituições oriundos ou sediados em países anglófonos e, particularmente, os Estados Unidos (Aalbers, 2004; Kauppi, N. \& Erkillä, 2011), dado que a produção científica de destaque é, em sua grande maioria, canalizada em veículos controlados por um pequeno número de agentes (Larivière, Haustein \& Mongeon, 2015). Nesse novo cenário, uma miríade de novos atores passou a influenciar a agenda da investigação: as Instituições Financeiras Internacionais (IFIs) com destaque para o Banco Mundial, ONGs e think tanks. Em conjunto, esses fatores contribuíram para estabelecer um ambiente extraordinariamente favorável para a legitimação de premissas neoliberais como saber acadêmico.

\section{Os Novos Influenciadores da Pesquisa Acadêmica}

No contexto da globalização neoliberal, um novo conjunto de atores passou a influenciar decisivamente a agenda da investigação acadêmica, de modo ainda mais intenso do que na etapa anterior. Dentre eles, destaca-se o papel que o Banco Mundial assumiu como fonte de conceitos e modelos analíticos que se espalharam por diversas disciplinas do campo das ciências humanas e sociais aplicadas. Isso se explica por dois motivos principais. De modo geral, essa condição deriva da centralidade de que o mercado desfruta como instituição social paradigmática no contexto do neoliberalismo: por um lado, a garantia de condições ótimas para o funcionamento do mercado constitui o objetivo primário de toda a política; 
por outro, entende-se que sua lógica deveria ser espelhada em todos os campos da vida social (Brown, 2005). Em termos concretos, o avanço do neoliberalismo favoreceu a supremacia dos economistas que, clamando dispor de métodos mais rigorosos de investigações do que os demais, reivindicaram exercer um papel de liderança no universo das ciências sociais (Fourcade, Ollion \& Argain, 2015).

Em particular, o Banco Mundial tem desempenhado um papel central no núcleo duro do processo de globalização neoliberal, sendo um dos principais integrantes do chamado Consenso de Washington, juntamente com o governo dos Estados Unidos e o FMI, que ajudou a promover a implantação compulsória de medidas neoliberais - disciplina fiscal, liberalização do comércio, privatização, desregulamentação, dentre outros - via mecanismos de condicionalidade, como pré-requisito para o recebimento de empréstimos por parte das IFIs (Williamson, 2008). A América Latina ofereceu o primeiro campo de testes sistemático para essas políticas, que contribuíram significativamente para a "década perdida" que a região experimentou nos anos 1990.

Dadas as reações negativas motivadas por esse estilo autoritário, o Banco Mundial mudou o seu estilo de atuação e se definiu como um Banco de Conhecimento (Knowledge Bank), cujo foco de atuação passou a ser oferecer consultoria para os governos, voltada para o aperfeiçoamento de suas práticas. A atuação do Banco Mundial envolveu inúmeros tópicos que, em seu conjunto, estendem o conceito de economia muito além do seu universo original, como parte do seu Comprehensive Development Framework (Cammack, 2002). Incluem-se aí a economia para o desenvolvimento (Lera St Clair, 2006) e o combate à pobreza (Dutta \& Rastogi, 2016), a promoção do Rule of Law (Santos, 2006), através do combate à corrupção (Bukowansky, 2015), a boa governança (Santos, 2006) e a liberdade de imprensa (Brunetti \& Weder, 2003; Norris, 2010). Ao fazê-lo, o Banco Mundial reivindica exercer o papel de "mãe de todos os governos" (Cammack, 2002). A despeito do seu regulamento proibir a intervenção em assuntos da política interna dos países, o Banco Mundial foi capaz de expandir o seu campo de atuação ao apresentar todos esses problemas como sendo de natureza fundamentalmente econômica (Rothstein, 2011).

Outros agentes se somaram ao Banco Mundial, num contexto em que os chamados atores não-estatais desempenham um papel cada vez mais ativo como formuladores/fiadores de 
políticas públicas e, desse modo, invadem campos de ação associados à autoridade do Estado Nacional e contribuem para minar a sua autoridade, visto que a sua atuação fundamentada em critérios de expertise técnica, antes que em mecanismos de consulta popular - criam mecanismos de poder e legitimidade que se sobrepõem, e por vezes confrontam com, aqueles que tradicionalmente se apresentam no âmbito do Estado Nação. Dentre eles podemos citar organizações não governamentais (ONGs), think tanks, agências internacionais de avaliação de risco financeiro e, mesmo, empresas de segurança privadas que exercem funções paramilitares (Hall \& Biersteker, 2002; Josselyn \& Wallace, 2001). No geral, esse movimento implicou em uma privatização de funções públicas. Igualmente, esses agentes privados passaram a desempenhar cada vez mais funções na produção do conhecimento antes reservadas à universidade.

Três exemplos merecem destaque aqui, em função da sua interface com elementos da crise política brasileira. O primeiro deles diz respeito ao National Endowment for Democracy (NED). Suas origens remetem a uma mudança estratégica no modo de atuação do governo americano ocorrida durante o primeiro governo de Ronald Reagan, inspirada num conceito de promoção de democracia que, naquela época, se confundia com a agenda do combate ao comunismo. Vinculado a um comitê bipartidário do Congresso Americano, e intimamente associado ao Departamento de Estado americano (Christensen, 2017), o NED exerce um papel ativo na promoção de eventos acadêmicos e edita a Journal of Democracy, uma revista ranqueada no Journal of Citation Reports, da Thomsom Reuters, que justapõe uma agenda acadêmica com outra, mais caracteristicamente política.

O segundo exemplo diz respeito à Freedom House, que, tal como o NED, mantém um vínculo estreito com o governo americano, responsável por prover dois terços dos seus recursos (Steiner, 2014) e conta com um número considerável de pessoas com experiência prévia no governo americano, particularmente nos setores militares, de inteligência e do Departamento de Estado em seu conselho diretor (Tsygankov \& Parker, 2014). O Índice de Liberdade da Imprensa (Freedom Press Index, ou FPI) se provou particularmente influente como ferramenta analítica, tanto na pesquisa acadêmica como por agências responsáveis pela implementação de políticas públicas, tanto em nível nacional como transnacional. Com enorme frequência, o uso dos dados do FPI serve para reafirmar o lugar privilegiado do Ocidente como centro normativo do mundo (para dois exemplos, ver Norris 
\& Inglehart, 2009; Sparks, 2015). Isso tudo acontece a despeito das inúmeras críticas feitas em relação à metodologia pouco rigorosa (e nada transparente) do FPI (Becker, 2003; Giannone, 2010) e seu viés sistemático, que desconsidera as limitações à liberdade da imprensa relacionadas à lógica da sociedade de mercado (Sapiezynska, \& Lagos, 2016), e beneficia as sociedades ocidentais em detrimento de outras sociedades (Giannone, 2010; Tsygankov \& Parker, 2014).

O último exemplo se refere à ONG Transparência Internacional (Transparency International), fundada em 1993 e que mantém íntimas relações com o Banco Mundial os ex-diretores do Banco Mundial Peter Elgen e Michael Wiehen estão entre seus fundadores. O mais importante produto da Transparência Internacional é o Índice de Percepção da Corrupção (Corruption Perception Index, ou CPI) que, do mesmo modo que o FPI, tem sido largamente empregado por pesquisadores acadêmicos e formuladores de políticas públicas. É importante observar que, embora o CPI seja frequentemente usado como uma medida objetiva da corrupção, na verdade trata-se de um índice de percepção da corrupção, elaborado com base em um público muito específico, constituído essencialmente por empresários. Trata-se, portanto, de um viés bastante específico sobre o tema. Ao lado disso, o CPI também tem sido criticado por desviar a atenção de aspectos muito importantes do problema, tais como o papel dos agentes privados no processo, os paraísos fiscais, fuga de capitais, evasão de impostos e o mundo financeiro offshore internacional responsável pela lavagem do dinheiro da corrupção. Além disso, o CPI contribuiria para reforçar preconceitos contra países não desenvolvidos, o que os tornaria ainda mais vulneráveis à manipulação política (Bukovansky, 2015).

Tais exemplos cobrem apenas uma pequena fração do universo de agentes que, de modo sistemático, têm se esforçado por influenciar a agenda de pesquisa acadêmica de modo a promover nela valores e premissas associadas à lógica da globalização neoliberal. Os casos mencionados dão conta de duas estratégias bastante comuns pelas quais esses agentes influenciam a pesquisa acadêmica: o controle de veículos importantes da produção acadêmica, e a manufatura de rankings, que emprestam uma aparência de objetividade e facticidade a interpretações que são, fundamentalmente, ideologicamente enviesadas. 


\section{Fundamentos Neoliberais da Agenda Acadêmica}

Dado o empenho com que, ao longo das últimas décadas um conjunto diverso de atores poderosos tem promovido, junto ao meio acadêmico, a sua agenda neoliberal, não é de surpreender que os conceitos e problemas teóricos por eles patrocinados tenham obtido uma ampla aceitação junto ao meio acadêmico. Em benefício da simplicidade, concentramos nossa atenção em três temas amplos, que recortam aspectos diferentes do discurso sobre a política e ao papel que cabe à comunicação desempenhar nela. $\mathrm{O}$ primeiro diz respeito a um conjunto de conceitos relacionados ao exercício virtuoso do governo, que inclui os conceitos de governança e accountability. $\mathrm{O}$ segundo se refere à lógica da judicialização da política, relacionada aos conceitos de Rule of Law e a questão da corrupção. O terceiro diz respeito às novas formas de participação política que se organizam em torno do ciberespaço.

O conceito de governança dá conta de uma apropriação da noção tradicional de governo à luz da lógica econômica neoliberal. Em linhas gerais o conceito põe em segundo plano o princípio representativo como fundamento do governo em benefício da dimensão da eficiência do governo (Williams \& Young, 1994). Como acontece com outros termos discutidos aqui, o Banco Mundial desempenhou um papel fundamental na formulação do conceito de governança, principalmente a partir da década de 1990, em resposta aos desafios apresentados pelo colapso da União Soviética e dos regimes comunistas da Europa Central e Oriental. Em particular, o conceito de governança estrategicamente esvazia o sentido político presente no conceito de governo, e o substitui por uma concepção que enfatiza o seu caráter administrativo e sua eficiência na administração de recursos econômicos. Nessa lógica, índices e rankings ganham relevância como instrumentos de avaliação da governança (Cooley \& Snyder, 2015, Santos, 2006). A relevância desse conceito para entender o recente processo de colapso da democracia fica evidente quando se considera que a crise de governabilidade foi um dos principais elementos que serviram para justificar o impeachment da presidente Rousseff, em um contexto em que as evidências de sua atuação ilegal pareciam muito frágeis - e depois se revelaram inexistentes. Por outro lado, o fato de o governo que se seguiu ter adotado ativamente 
reformas de caráter neoliberal parece ter contribuído para poupar o governo seguinte das mesmas críticas.

O conceito de accountability ganhou ampla circulação na esteira do processo de redemocratização iniciado em meados da década de 1970 - conhecido como "terceira onda" da redemocratização (Huntington, 1991), e teve em Guillermo O'Donnell um dos seus principais promotores, como parte do esforço de evitar que esse processo resultasse no triunfo da lógica da democracia delegativa, como vimos acima. Essa perspectiva é consistente com a tradição estabelecida na ciência política americana de perceber as instituições políticas como freio ao exercício imoderado da vontade popular. Na medida em que a concepção de governo técnico ganhava terreno, na esteira da globalização neoliberal, a accountability passou a cada vez mais ser tomada como praticamente um sinônimo de democracia (ver Mainwaring \& Welna, 2003) - ou pelo menos uma forma mais evoluída desta, um "governo pela publicidade" (Filgueiras, 2011). Kellam e Stein (2016) apresentam uma versão extrema desse argumento geral, em sua análise das relações entre presidentes e imprensa na América Latina, não apenas porque elas tomam o índice de liberdade da imprensa da Freedom House como critério para avaliar a qualidade da democracia em determinados países, mas porque as autoras sugerem que governos de esquerda eleitos por ampla maioria são mais propensos a limitar a liberdade de imprensa. O ponto a se destacar aqui é que tais análises legitimam a hipertrofia das instituições de controle, seja as situadas no aparato de Estado - Judiciário, Ministério Público, Polícia Federal, dentre outras - ou fora dele, como a imprensa e, portanto, apresentam imensos limites conceituais para dar conta de um processo como o que aconteceu no Brasil, na qual os agentes da accountability ativamente conspiraram contra a ordem democrática (Albuquerque, 2017).

O segundo conjunto temático de grande relevância diz respeito aos conceitos de Rule of Law e corrupção. Embora o conceito de Rule of Law tenha uma longa história na tradição ocidental, o seu uso contemporâneo dá conta de uma interpretação muito específica patrocinada pelo Banco Mundial a partir da década de 1990, entendida como "uma ordem legal que consiste de regras previsíveis, praticáveis e eficientes, necessária para que a economia de mercado possa florescer (Santos, 2006: 253). Em particular, o Rule of Law é associado à existência de um Judiciário independente, "capaz de tornar os detentores de 
poder accountable em relação às regras do jogo" (Gloppen, Gargarella \& Skaar, 2004). Governos ocidentais - e especialmente o governo americano, através de sua Agência para o Desenvolvimento Internacional e os Departamentos de Estado e de Comércio - se empenharam ativamente em promover reformas no sistema legal de países da Europa Oriental e antiga União Soviética, e também na Ásia e na América Latina a título de "ajuda legal" (Carothers, 1998). A questão da democracia ocupa um lugar secundário na definição do Banco Mundial. De fato, Ferejohn e Pasquino (2003) sustentam que a Rule of Law se sustenta em princípios fundamentalmente distintos da Rule of Democracy.

Não apenas a legitimidade do Judiciário se ancora em uma lógica fundamentalmente técnica como, em última análise, remete a uma ordem transnacional, na qual IFIs e governos de países ocidentais. Isso não significa, contudo, que essa lógica judiciária tenha se reproduzido de maneira idêntica por toda parte. Ao contrário, em muitos casos, o apelo à retórica do Rule of Law permitiu a setores do Judiciário reivindicar poder em seus próprios termos. Em particular, tendo por referência o caso brasileiro, Santiso (2004) destacou os riscos que resultam da adoção dessa concepção, quando o Judiciário põe sua independência acima dos seus deveres de accountability. O golpe de 2016 demonstrou tragicamente o enorme potencial corrosivo que um grau extremo de autonomia judicial pode ter em relação à preservação do regime democrático (Engelmann, 2016).

O conceito de corrupção se define negativamente em relação ao de Rule of Law. Embora o tema da corrupção tenha uma longa história, seu uso recente dá conta de uma apropriação fundamentalmente econômica, antes que moral do termo. De acordo com o Banco Mundial, a corrupção acontece quando autoridades oferecem ou recebem suborno e "mesmo se não houver suborno, através de clientelismo e nepotismo, o roubo de recursos do Estado ou o desvio de rendas do Estado" (1997: 8-9). Embora reconheça que o suborno também ocorre no setor privado, o Banco Mundial defende essa definição restrita de corrupção com base no argumento tautológico de que ela é simples e ampla o suficiente para dar conta da maior parte da corrupção que ele encontra - talvez porque seja a que ele está procurando. Tal definição é relevante tanto pelo que destaca quanto pelo que omite. A corrupção é associada fundamentalmente ao Estado, antes que aos agentes privados, à política como fator que perturba a ordem econômica e a relações que têm lugar no interior de fronteiras nacionais, antes que em um âmbito transnacional. Essa definição restrita de corrupção animou boa 
parte das ações levadas a cabo na Operação Lava Jato, visto que o seu foco recaiu fundamentalmente sobre as atividades de corrupção envolvendo personagens políticos, ao mesmo tempo em que as empresas privadas que teoricamente se beneficiariam dela ficaram em um segundo plano. De resto, acusações de corrupção estiveram por trás de diversas ações de cunho golpista realizadas em diversos outros países, tais como Ucrânia e Honduras.

O terceiro tema que importa discutir aqui diz respeito aos modelos de atuação pública centrados no ciberespaço. À primeira vista a relação desse tema com a agenda neoliberal pode parecer um tanto quanto remota. Contudo, um olhar mais atento sobre a origem do ciberespaço deixa esses laços bastante visíveis. Como observou Vincent Mosco (2004), o advento do ciberespaço veio associado ao mito do fim da política - pelo menos na sua concepção tradicional, estruturada em torno de instituições formais, estruturadas de maneira hierárquica. $\mathrm{O}$ dado a se destacar é que o projeto do ciberespaço envolveu um engajamento ativo por parte do aparato de defesa dos Estados Unidos (Strategic Defense Initiative, SDI) e do think tank Progress and Freedom Foundation (PFF), cujos membros eram ligados (e por vezes integrantes) do Partido Republicano e bastante influentes no governo Reagan - e cujos financiadores incluem muitas das indústrias de mídia e tecnologia da informação mais importantes daquele país (Oracle, IBM, Amazon, MGM, dentre outras). Em particular, o PFF patrocinou ativamente uma concepção de democracia direta que valorizava demandas relacionadas ao âmbito do privado - relacionadas aos interesses dos indivíduos - sobre aquelas de caráter mais público. O impacto dessa agenda sobre o debate acadêmico foi extraordinário. Por exemplo, a questão focal da pesquisa sobre a relação entre internet e partidos políticos disse respeito fundamentalmente à capacidade das tecnologias digitais de empoderar os indivíduos frente as estruturas partidárias - definida como equalização para o caso positivo ou normalização para o negativo (Albuquerque e Martins, 2010). A agenda neoliberal do ciberespaço chegou a influenciar mesmo a análise de autores usualmente associados a pautas de esquerda: na obra de Castells (2015) e Bennett \& Segerberg (2012), cujas obras definem os modelos de ação conectiva, baseados na agregação de interesses individuais e hostis à hierarquia como o modelo predominante de ação política em nosso tempo. 


\section{Os Fundamentos Neoliberais da Pesquisa Brasileira em Comunicação Política}

Nesta seção, argumento que boa parte da pesquisa brasileira em Comunicação Política está solidamente ancorada em premissas associadas a uma perspectiva neoliberal, patrocinadas por agentes politicamente interessados. Não se trata, porém, de sugerir que os pesquisadores brasileiros endossem pessoalmente tais perspectivas, mas, antes, que eles dispõem pouco controle sobre a sua agenda de investigação, na medida em que raramente questionam os fundamentos históricos ou conceituais que a sustentam. Tudo se passa como se sua agenda acadêmica adquirisse vida própria, de modo que, quaisquer que sejam as convicções pessoais do pesquisador, elas se afastam daquelas a que chegam o seu esforço de investigação.

Um exemplo concreto: se examinarmos a atuação dos pesquisadores brasileiros nas mídias sociais, restará pouca dúvida de que um número substancial deles acredita que a democracia brasileira experimenta atualmente uma crise de grandes proporções; se, contudo, considerarmos a produção científica recente na Comunicação Política, a impressão geral será, provavelmente, de que o país passa por um período de normalidade democrática, com indicadores que sugerem mesmo a possibilidade de um aperfeiçoamento das instituições políticas. Dentro dos limites deste artigo, importa-nos destacar alguns exemplos de que essa agenda tem afetado a pesquisa nacional para, em seguida, explorar alguns motivos pelos quais essa situação ocorre.

Um primeiro aspecto a se destacar diz respeito à virada cyber nos estudos de Comunicação Política (Gomes, 2016a; Sampaio, Bragatto \& Nicolás, 2016). Por virada cyber, entendese aqui não apenas um foco crescente na internet como veículo/instrumento de comunicação política, mas análises que, em última análise, ecoam premissas associadas à concepção neoliberal do ciberespaço. Uma das formas mais notáveis de manifestação desse fenômeno remete à excepcional atenção que foi destinada às manifestações de 2013: literalmente, dezenas de textos foram publicados sobre o tema em um curto intervalo de tempo e, com enorme frequência, essas obras ecoam a retórica hype que marcou aquelas manifestações (“não é só por vinte centavos”, “o gigante acordou...”), e as descrevem como 
um momento de virada na construção de uma nova prática política, efetivamente democrática porque baseada no "povo na rua" no país (dentre diversos outros exemplos, podemos mencionar Malini \& Antoun, 2013; Peruzzo, 2013; Santos \& Aldé, 2016).

É, de fato, fascinante como, tão pouco tempo depois, os relatos que esses textos fazem das manifestações de 2013 parecem se referir a um mundo exótico e distante - o que não impede que mais textos sobre o tema continuem a ser publicados. É justo mencionar que a pesquisa brasileira sobre o tema acompanha de perto tendências mais gerais, da literatura internacional e que esta também se revelou inteiramente inepta para avaliar o real impacto das manifestações que, de certo modo, serviram de inspiração para a brasileira. Não custa lembrar que a tão aclamada Primavera Árabe foi, em quase toda parte, seguida por cruentas guerras civis, como na Síria e na Líbia, ou da instauração de regimes autoritários extremamente repressivos, como no Egito (ver, por exemplo, Gerbaudo, 2013). Viradas conservadoras também caracterizaram outros países cujas experiências foram saudadas pela literatura, como os Estados Unidos do Occupy e a Espanha do movimento dos Indignados.

Um segundo aspecto, estreitamente relacionado ao primeiro, diz respeito à importância crescente que temas relacionados às esferas privada e íntima recebem como campo privilegiado do político, em detrimento da dimensão institucional da política. Em particular, questões relativas à política do corpo e outras questões identitárias (Leal, 2016; Maia \& Castro, 2016; Sarmento \& Mendonça, 2017) ganham grande importância, a expensas das instituições políticas tradicionais.

A coletânea Reinvenção Comunicacional da Política. Modos de habitar e desabitar o século XXI (Jesus, Trindade, Janotti Jr \& Roxo, 2016) fornece um exemplo particularmente expressivo dessa tendência, já que inclui entre seus capítulos títulos como "Lady Gaga em Cuba", "Mídia Ninja e juventude: corpos e afetos na disputa política e nas narrativas audiovisuais" e "A Primavera Árabe e o enquadramento do outro: a captação da alteridade na narrativa jornalística”, não conta com um único capítulo que mencione as instituições políticas tradicionais. O problema, aqui, não é que agendas identitárias sejam desprovidas de mérito político, mas que, como o governo que se seguiu ao golpe de 2016 tem demonstrado claramente, sua eficácia se torna letra morta na ausência de condições 
institucionais favoráveis. Naturalmente, não se trata de uma regra absoluta: tendo em vista o caso da Marcha das Vadias, Rizotto, Prudêncio e Silva (2016) oferecem um exemplo relevante de texto que considera essas pautas tendo em vista seu alcance e seus limites, que se estabelecem na promoção dessa agenda.

Não apenas as pautas que se tornam objeto da atenção acadêmica mudaram, mas também o tipo de abordagem desenvolvida acerca dos agentes políticos e seu modo de atuação. $\mathrm{O}$ foco, aqui, recai frequentemente sobre a dimensão do "alternativo" e da "novidade". Dois tipos de agentes encarnam de maneira privilegiada esses valores. O primeiro corresponde aos hackers (Castelfranchi, 2017; Silveira, 2010), cujo caráter contra-hegemônico é frequentemente tomado como dado; o segundo diz respeito aos novos coletivos que se estruturam através de uma lógica agregativa e multi-pautas (Santos \& Aldé, 2016). Uma enorme parcela desses textos encontra no conceito de modelo de ação conectiva, proposto por Bennett e Segerberg (2012) o seu kit analítico padrão. O referencial teórico proposto por esses autores tem o inegável mérito de propor um modelo para dar conta da interface entre a internet e o mundo da rua, o online e o offline, embora tenha muito pouco a dizer sobre o modo como essas ações poderiam se traduzir em mudanças sociais concretas - e talvez não seja por acaso que os movimentos inspirados por essa lógica tenham fracassado em atingir os seus objetivos em toda parte. Adicionalmente, é digno de nota que o uso desses recursos por setores conservadores e de ultradireita permanece, no fundamental, praticamente ignorado (para uma exceção ver Santos, 2016).

Outro conjunto de textos parece tomar o universo online como um espaço autossuficiente de mobilização política, sem praticamente qualquer referência a práticas concretas que se realizariam para além dele. Eles incluem campanhas online (Leal, 2016); disputas travadas em torno de hashtags (D’Andrea, Alzamora \& Ziller, 2015) e memes (Chagas \& Santos, 2017; Sarmento \& Chagas, 2017). Mais uma vez, o problema não são os textos em si mesmos, mas tomados em seu conjunto eles contribuem para legitimar uma perspectiva reativa sobre a militância política, baseada numa lógica individualista, e que substitui estratégia por efeitos estéticos. O brutal retrocesso político que o Brasil experimentou nos últimos anos é evidência da inefetividade concreta de ações como o "vomitaço". 
Um terceiro conjunto de abordagens se aproxima da lógica neoliberal de uma maneira inteiramente diferente. Longe de centrar a sua atenção em movimentos de contestação ou afirmação identitária, o seu foco recai sobre instituições políticas, consideradas do ponto de vista das suas ações e ferramentas destinadas a promover transparência/accountability, ou estimular a participação cidadã no debate dos temas públicos. Esse conjunto é, provavelmente, o mais articulado e o que reúne mais pesquisadores no país, em torno da agenda da e-democracia (Gomes, 2016a). Um número imenso de trabalhos tem dado conta das dinâmicas participativas digitais que se constituem a partir de iniciativas de consulta pública governamental (Sampaio, Maia \& Marques, 2010; Steibel, 2014), iniciativas de transparência pública e dados abertos (Filgueiras, 2017; Possamai, 2016), e o emprego dos recursos digitais como instrumento de ampliação da representação por instâncias dos Poderes Executivo e Legislativo (Braga e Cruz, 2014; Farias, Rodrigues \& Sahler, 2016; Mitozo, Marques \& Mont'Alverne, 2016).

Poder-se-ia dizer que, ao contrário dos textos mencionados previamente, esse conjunto de pesquisas centra o seu foco nas instituições políticas. Contudo, isso não é plenamente verdadeiro, uma vez que essas instituições são consideradas a partir de um ângulo muito específico - da sua comunicação digital - que pouco tem a ver com as práticas concretas que têm lugar nelas. De fato, a ideia de que instituições que desempenharam um papel ativo no golpe de 2016, como o Senado Federal ou a Câmara dos Deputados sejam, em seu braço digital, agentes da ampliação da cidadania e do aperfeiçoamento da qualidade da democracia soa um tanto exótica. Torna-se evidente um descompasso entre a agenda da investigação e o momento histórico em que ela ocorre. A agenda da e-democracia - o uso dos recursos digitais como instrumento de aprofundamento da democracia - parecia sensata em um contexto em que a democracia parecia uma conquista assegurada. Em circunstâncias como as que existem atualmente, contudo, ela pode soar como desprovida de sentido.

Um último conjunto de trabalhos que merece destaque diz respeito ao jornalismo. Uma análise da produção recente de periódicos especializados como a Revista Compolítica, Estudos de Jornalismo e Mídia e Brazilian Journalism Research indica que a noção de crise do jornalismo e perspectivas críticas sobre a performance das instituições jornalísticas na democracia permanecem quase inexistentes - Mick e Tavares (2017) oferecem um raro 
exemplo de trabalho que têm na crise do jornalismo o seu problema central, mas o fazem com base na categoria neoliberal de governança, tal como formulada por Mark Bevir (2010). No geral, o leitor de periódicos brasileiros terá a nítida impressão de que o jornalismo vivencia um excelente momento, e talvez mesmo sua idade do ouro se considerarmos a imensa quantidade de artigos que mencionam novas práticas estruturadas com base no jornalismo com base de dados, crowdfunding e práticas de jornalismo cidadão. A consolidação desse tipo de abordagem tem muito a ver com a forma como a pesquisa sobre o jornalismo se constituiu no Brasil, numa lógica que subordina a pesquisa acadêmica à identidade profissional do jornalista. Nessa lógica, a teoria do jornalismo só pode ser realizada por jornalistas-pesquisadores (nessa ordem); todo o resto é apenas "estudos sobre o jornalismo" (Machado, 2004).

Especificamente no que diz respeito à democracia, a ausência de um posicionamento crítico dos pesquisadores brasileiros em relação à atuação da imprensa no processo de desconstrução da democracia é digno de atenção - para uma das poucas exceções ver Azevedo (2017). Merece atenção também o fato de que pesquisadores estrangeiros têm sido mais sensíveis ao tema que os brasileiros (por exemplo Goldstein, 2017; Van Dijk, 2017). De fato, é interessante contrastar o tom extraordinariamente moderado com que pesquisadores brasileiros se posicionam sobre o tema - Christofoletti (2016), por exemplo, usa o termo "risco ético" para qualificar a atuação da imprensa - com o modo fortemente engajado com que pesquisadores dos Estados Unidos e do Reino Unido (que no final das contas fornecem o parâmetro de cientificidade em escala global) se posicionaram diante do escândalo do News of the World ou à eleição e ao governo de Donald Trump.

Para além disso, é possível encontrar um número considerável de trabalhos que relativizam a ideia de que a atuação da imprensa tenha sido parcial nos últimos anos ou mesmo que louvam a sua contribuição para a democracia. No primeiro caso, pode-se mencionar o argumento de Gomes (2016b) que defende a ideia de que a atuação parcial da mídia brasileira é antes o produto de uma impressão subjetiva do que uma maneira válida de descrever o seu comportamento efetivo. Outros autores louvam ativamente a atuação política da imprensa nos últimos anos: para Araújo, Costa e Fittipaldi (2016), por exemplo, a imprensa atuou como um verdadeiro agente de accountability a serviço da democracia, em suas denúncias contra a corrupção do governo de Dilma Rousseff; Trasel (2018) 
enaltece o trabalho dos profissionais do núcleo de jornalismo de dados d'O Estado de $S$. Paulo como inspirado na cultura hacker; Mitozo, Braga e Vieira (2017) elogiam a contribuição da plataforma Candibook, do jornal paranaense Gazeta do Povo - o mesmo que recentemente iniciou uma campanha de caça às bruxas contra professores universitários - como um serviço valioso de monitoramento da democracia pelos eleitores.

\section{Conclusão}

O golpe jurídico-parlamentar que resultou no impeachment da presidente eleita Dilma Rousseff pegou de surpresa os pesquisadores brasileiros em diversas áreas de pesquisa, inclusive na comunicação política. Como e por que isso pôde acontecer? Argumentamos aqui que o problema se deve à incapacidade da pesquisa brasileira em definir a própria agenda de investigação. Isso acontece por duas razões: do lado da demanda, o Brasil se constitui como um país periférico no cenário internacional da pesquisa, e essa condição torna os pesquisadores brasileiros particularmente propensos a reproduzir, de maneira pouco crítica, premissas e modelos cunhados para dar conta de condições inteiramente diferentes das que se apresentam no seu país; do lado da oferta, desde o final da Segunda Guerra Mundial, um conjunto diversificado de atores - que inclui instituições filantrópicas, think tanks, ONGs, IFIs e agências do governo dos Estados Unidos - tem, ativa e sistematicamente, promovido agendas acadêmicas politicamente orientadas.

O ponto a se destacar é que, como tudo mais, a agenda da pesquisa acadêmica é um fenômeno historicamente situado e, portanto, sujeito a mudanças. A agenda atual reflete, em primeiro lugar, a ordem unipolar que se constituiu a partir da aliança entre o governo dos Estados Unidos e as IFIs no contexto da globalização neoliberal e, em segundo, expectativas otimistas quanto à consolidação e o aperfeiçoamento da democracia no Brasil, que ganharam impulso especial durante os governos recentes, em função de iniciativas como a política de ação afirmativa e o Marco Civil da internet. Nesse contexto, agendas de investigação como a da e-democracia fazem sentido. Quando as circunstâncias históricas mudam, a necessidade de rever as premissas da investigação se tornam imperiosas. 
Em termos globais, na medida em que a ordem unipolar constituída dos Estados Unidos mostra claros sinais de crise, a naturalização de modelos sociais cunhados e patrocinados nesse país perdem muito a sua razão de ser. Da perspectiva brasileira, o problema vai ainda além: não apenas a agenda de pesquisa impediu (e ainda impede) os pesquisadores de entender o papel que as instituições de accountability desempenharam no processo de desconstrução da democracia brasileira - ironicamente, em nome da "democracia de qualidade" - como, de fato, a sua consequência natural é legitimar esses mesmos agentes. Dolorosas como sejam, crises como a que experimentamos hoje, no Brasil, trazem ao menos uma ocasião para examinarmos nossas práticas acadêmicas.

\section{Referências}

AALBERS, M. B. Creative destruction through the Anglo-American hegemony: a non-AngloAmerican view on publications, referees, and language. Area 36(3): 319-322, 2004.

ALBUQUERQUE, A. de. Another Fourth Branch: Press and Political Culture in Brazil. Journalism 6(4): 486-504, 2005.

ALBUQUERQUE, A. de; MARTINS, A. F. Apontamentos para um modelo de análise dos partidos na web. Anais do XIX Encontro Anual da Compós, Rio de Janeiro, 2010.

ALBUQUERQUE, A. de. Protecting democracy or conspiring against it? Media and politics in Latin America: A glimpse from Brazil. Journalism DOI: 10.1177/1464884917738376, 2017.

AMSLER, S. S.; BOLSMANN, C.. University ranking as social exclusion. British Journal of Sociology of Education 33(2): 283-301, 2012.

ARANTES, R. B. Direito e Cidadania: o Ministério Público e a defesa dos direitos coletivos. Revista Brasileira de Ciências Sociais 14(39): 83-102, 1999.

ARANTES, R. B. "The Federal Police and the Ministério Público", in POWER, T.; TAYLOR, M. (orgs.), Corruption and Democracy in Brazil. Notre Dame, University of Notre Dame Press, pp. 184-217, 2010.

ARAÚJO, C. M.; COSTA, S. F.; FITTIPALDI, I. Boa noite, e boa sorte: determinantes da demissão de ministros envolvidos em escândalos de corrupção no primeiro governo Dilma Rousseff. Opinião Pública 22(1): 93-117, 2016.

AVRITZER, L.; MARONA, M.. A Tensão entre a Soberania e Instituições de Controle na Democracia Brasileira. Dados 60(2): 359-393, 2017.

AZEVEDO, F. A grande imprensa e o PT (1989-2014). São Carlos: Edufscar, 2017.

BECKER, C. C.; M, GALLAS, D.; WEBER, M. H. Manifestações e votos ao impeachment de Dilma Rousseff na primeira página de jornais brasileiros. Revista Alaic 13(24): 97-113, 2017. 
BECKER, J. Keeping Track of Press Freedom. European Journal of Communication 18(1): 107112, 2003.

BENNETT, W. L \& SEGERBERG, A. The Logic of Connective Action. Digital Media and the Personalization of Contentious Politics. Cambridge: Cambridge University Press, 2012.

BEVIR, M. Democratic Governance. Princeton: Princeton University Press, 2010.

BOAS, T. C. Mass media and politics in Latin America. In: DOMÍNGUEZ, J.; SHIFTER, M. (eds). Constructing Democratic Governance in Latin America. Baltimore, MD: Johns Hopkins University Press, pp. 48-77, 2013.

BOURDIEU, P.; WACQUANT, L. On the Cunning of Imperialist Reason. Theory, Culture \& Society 19(1): 41-58, 1999.

BRAGA, S.; CRUZ, L. C. As tecnologias digitais e o mandato dos representantes. In SILVEIRA, S. A.; BRAGA, S.; PENTEADO, C. Cultura, política e ativismo nas redes digitais. São Paulo: Editora Fundação Perseu Abramo, p. 145-176, 2014.

BROWN, W. Edgework: Critical Essays on Knowledge and Politics. Princeton: Princeton University Press, 2005.

BRUNETTI, A.; WEDER, B. A free press is bad news for corruption. Journal of Public Economics 87(7/8): 1801-1824, 2003.

BUKOVANSKY, M. Corruption rankings: Constructing and contesting the global anti-corruption agenda. In COOLEY, A, SNYDER, J. (Eds.). Ranking the World: Grading States as a Tool of Global Governance. Cambridge: Cambridge University Press, 2015.

CAMMACK, P. The mother of all governments: The World Bank's matrix for global governance. In RORDEN, W.; HUGHES, S. (eds). Global Governance: Critical Perspectives. Londres e Nova lorque: Routledge, p 36-53, 2002.

CAROTHERS, T. The Rule of Law Revival. Foreign Affairs 77: 95-107, 1998.

CASTELFRANCHI, Y. "Política hacker" O desafio da cidadania tecnocientífica na democracia contemporânea In MENDONÇA, R. F.; PEREIRA, M. A.; FILGUEIRAS, F. (ed.) Democracia digital: publicidade, instituições e confronto político. Belo Horizonte: Ed. da UFMG, pp. 307-332, 2017

CASTELLS, M. Networks of Outrage and Hope. Social Movements in the Internet Age. Chichester (UK): John Willey \& Sons, 2012.

CHAGAS, V.; SANTOS, J. G. B. Veni, vidi, vomiti: ocupações, desobediência civil e ativismo escatológico do Vomitaço. Trabalho apresentado no XXVI Encontro Anual da Compós, São Paulo, 2017.

CHRISTENSEN, M. Interpreting the Organizational Practices of North American Democracy Assistance. International Political Sociology 11 (2): 148-165, 2017.

CHRISTOFOLETTI, R. Riscos éticos em tempos de delações, vazamentos e clamor por transparência. Brazilian Journalism Research 12(2): 58-77, 2016. 
CONNELL, R. A iminente revolução na teoria social. Revista Brasileira de Ciências Sociais 27(80): 9-20, 2012.

COOLEY, A; SNYDER, J. Eds. Ranking the World: Grading States as a Tool of Global Governance. Cambridge: Cambridge University Press, 2015.

DAHL, R. (1997). Poliarquia: Participação e Oposição. São Paulo: Editora da Universidade de São Paulo.

D'ANDREA, C.; ALZAMORA, G.; ZILLER, J. (2015) Hashtags as Intermedia Agency Resources before FIFA World Cup 2014 in Brazil. In RAMBUKKANA, R. Hashtag Publics. The Power and Politics of Discursive Networks. New York: Peter Lang, p. 115-126.

DUTTA, M.; RASTOGI, R. Deconstructing PRSP Measurement: Participation as Neoliberal Colonization. Journal of Creative Communications 11(3): 211-226, 2016.

ENGELMANN, F. Julgar a Política, Condenar a Democracia? Justiça e Crise no Brasil. Conjuntura Austral 7(37): 9-16, 2016.

FARIAS, C. F.; RODRIGUES, M. R.; SATHLER, A. R. In SILVA, S. P.; BRAGATTO, R. C.; SAMPAIO, R. C. (eds.). Democracia Digital, Comunicação Política e Redes: Teoria e Prática. Rio de Janeiro: Folio Digital, p. 393-418, 2016.

FEREJOHN, J.; PASQUALE, P. Rule of Democracy and Rule of Law. In MARAVALL, J.M; PRZEWORSKI, A (eds.). Democracy and the Rule of Law. Cambridge: Cambridge University Press, 2003.

FILGUEIRAS, F. Além da transparência: accountability e política da publicidade. Lua Nova 84: 65-94, 2011.

FILGUEIRAS, F. A política pública de transparência no Brasil. Tecnologias, publicidade e accountability. In Mendonça, R. F.; Pereira, M. A. \& Filgueiras, F. (ed.) Democracia digital: publicidade, instituições e confronto político. Belo Horizonte: Ed. da UFMG, pp. 79-112, 2017.

FOURCADE, M.; OLLION, E.; ALGAN, Y. The Superiority of the Economists. Journal of Economic Perspectives 29(1): 89-114, 2015.

GARY, B. Communication Research, the Rockefeller Foundation, and Mobilization for a War of Words, 1938-1944. Journal of Communication 46(3): 124-148, 1996.

GERBAUDO, P. The Impermanent Revolution: The Organizational Fragility of the Egyptian Prodemocracy Movement in the Troubled Transition. Social Justice 39(1): 8-23, 2013.

GIANONNE, D. Political and ideological aspects in the measurement of democracy: The Freedom House Case. Democratization 17(1): 68-97, 2010.

GILBOA, E. The CNN Effect: The Search for a Communication Theory of International Relations. Political Communication 22(1): 27-44, 2005.

GLOPPEN, S.; GARGARELLA, R.; SKAAR, E. Democratization and the Judiciary: The Accountability Function of Courts in New Democracies. London. Portland (OR): Frank Cass, 2004. 
GOLDSTEIN A. A. Prensa Tradicional Y Liderazgos Populares Em Brasil. Raleigh, NC: Editoral A Contracorriente, 2017.

GOMES, W. 20 anos de política, Estado e democracia digitais: uma "cartografia" do campo. In SILVA, S. P.; BRAGATTO, R. C.; SAMPAIO, R. C. (eds.). Democracia Digital, Comunicação Política e Redes: Teoria e Prática. Rio de Janeiro: Folio Digital, p. 39-76, 2016a.

GOMES, W. Por que a mídia é tão parcial e adversária da minha posição? A hipótese do "hostile media perception". Revista Compolítica 6(1): 7-28, 2016b

HALL, B.; BIERSTEKER, T. eds. The Emergence of Private Authority in Global Governance. Cambridge: Cambridge University Press, 2002.

HUGHES, S.; LAWSON, C. The barriers to media opening in Latin America. Political Communication 22(1): 9-25, 2005.

HUNTINGTON, S. P. The Third Wave: Democratization in the Late Twentieth Century. Norman (OK): Oklahoma University Press, 1991.

ISAAC, J. The Human Sciences in Cold War America. The Historical Journal 50(3): 725-746, 2007.

JESUS, E.; TRINDADE, E.; JANOTTI Jr., J.; ROXO, M. Reinvenção Comunicacional da Política. Modos de habitar e desabitar o século XXI. Salvador: EDUFBA, 2016.

JOSSELYN, D.; WILLIAM W., eds. Non-State Actors in World Politics. New York: Palgrave, 2001.

KAUPPI, N.; ERKILLÄ, T. The Struggle over Global Higher Education: Actors, Institutions and Practice. International Political Sociology 5(3): 314-326, 2011.

KELLAM, M; STEIN, E. Silencing Critics: Why and How Presidents Silent Media in Democracies. Comparative Political Studies 49(1): 36-77, 2016.

KHURANA, R.; KIMURA, K.; FOURCADE, M. How Foundations Think: The Ford Foundation as a Dominating Institution in the Field of American Business Schools. Harvard Business School Working Paper Series, 2011.

KRAMARZ, T.; MOMANI, B. "The World Bank as Knowledge Bank: Analyzing the Limits of a Legitimate Global Knowledge Actor". Review of Policy Research 30(4): 409-431, 2013.

KRIGE, J. American Hegemony and the Postwar Reconstruction of Science in Europe. Boston: The MIT Press, 2006.

LARIVIĖRE, V., HAUSTEIN, S. \& MONGEON, P. The Oligopoly of Academic Publishers in the Digital Era. Plos One. 10(6): e0127502. doi:10.1371/ journal.pone.0127502, 2015.

LAUF, E. National Diversity of Major International Journals in the Field of Communication. Journal of Communication 55(1): 139-151, 2005.

LAWSON, C. Building the Fourth Estate: Democratization and the Rise of a Free Press in Mexico. Berkeley, CA: University of California Press, 2002. 
LEAL, T. "Chega de fiu fiu": feminismo, emoções e mobilização política por meio de práticas de compartilhamento de si. In JESUS, E.; TRINDADE, E., JANOTTI Jr., J.; ROXO, M. Reinvenção Comunicacional da Política. Modos de habitar e desabitar o século XXI. Salvador: EDUFBA: 97112, 2016.

LERA St. CLAIR, A. The World Bank as a Transnational Expertised Institution. Global Governance 12(1): 77-95, 2006.

LERNER, D. The Passing of the Traditional Society: Modernizing the Middle East. New York: Free Press, 1958.

LIPSET, S. M. Political Man: The Social Bases of Politics. New York: Doubleday \& Company, 1960.

MACHADO, E. Dos estudos sobre o jornalismo às teorias do jornalismo (Três pressupostos para a consolidação do jornalismo como campo de conhecimento). E-Compós 1.

http://www.compos.org.br/seer/index.php/e-compos/article/view/2/4, 2004

MAIA, R.; CASTRO, M.C.P.S., eds. Mídia, esfera pública e identidades coletivas. Belo Horizonte: Editora UFMG, 2006.

MAIA, R.; ROSSINI, P. G. C., OLIVEIRA, V. V.; OLIVEIRA, A. G. Confronto político e mídia digital: investigando o "nós" da ação coletiva. JESUS, E.; TRINDADE, E., JANOTTI Jr., J.; ROXO, M. Reinvenção Comunicacional da Política. Modos de habitar e desabitar o século XXI. Salvador: EDUFBA, p.47-63, 2016.

MAINWARING, S.; WELNA, C., eds. Democratic accountability in Latin America. Oxford: Oxford University Press, 2003.

MALINI, F.; ANTOUN, H. (2013) A internet e a rua: ciberativismo e mobilização nas redes sociais. Porto Alegre: Sulina, 2013.

MARGINSON, S; van der WENDE, M. To Rank or To Be Ranked: The Impact of Global Rankings in Higher Education. Journal of Studies in International Education 11(3-4): 306-329, 2007.

MARQUES, F. P. J., MONT'ALVERNE, C.; MITOZO, I. B. "Nem Dilma, nem Temer”: Um estudo quantitativo sobre padrões de cobertura do impeachment de Dilma Rousseff em editoriais jornalísticos. In NAPOLITANO, C. J.; VICENTE, M. M. \& SOARES, M. C. (eds.). Comunicação \& Cidadania Política. São Paulo: Editora Cultura Acadêmica, p. 101-126, 2017.

MICELI, S. ed. A Fundação Ford no Brasil. São Paulo: Editora Sumaré e FAPESP, 1993.

MICK, J.; TAVARES, L. M. A governança do jornalismo e alternativas para a crise. Brazilian Journalism Research 13(2): 120-145, 2017.

MITOZO, I. B; BRAGA, S. S.; VIEIRA, F. A. Jornalismo online e eleições em 2014: uma análise a partir da iniciativa Candibook, do jornal Gazeta do Povo. Revista Brasileira de Ciências da Comunicação 40(3): 169-188, 2017.

MITOZO, I. B.; MARQUES, F. P. J.; MONT'ALVERNE, C. Como se configura a comunicação online entre representados e representantes no Brasil? Um estudo sobre a ferramenta digital da Câmara dos Deputados. Contracampo 35(2): 88-115, 2016. 
NERONE, J. C. Last Rights: Revisiting Four Theories of the Press. Chicago: University of Illinois Press, 1995.

NORRIS, P., ed. Public Sentinel: News Media \& Governance Reform. Washington (DC): The World Bank, 2010.

NORRIS, P. \& INGLEHART, R. Cosmopolitan Communications: Cultural Diversity in a Globalized World. Cambridge: Cambridge University Press, 2009.

O'DONNELL, G. (1991). Democracia Delegativa? Novos Estudos CEBRAP 31: 25-40, 1991.

O'DONNELL, G. Accountability horizontal e novas poliarquias.. Lua Nova 44: 27-54, 1998.

PAASI, A. Globalisation, academic capitalism, and the uneven geographies of international journal publishing spaces. Environment and Planning 37(5): 769-789, 2005.

PERUZZO, C. M. K. Movimentos sociais, redes virtuais e mídia alternativa no junho em que "o gigante acordou"(?). Matrizes 7(2): 73-93, 2013.

PETERS, J. D. Institutional Sources of Intellectual Poverty on Communication Research. Communication Research 13(4): 527-559, 1986.

PITTS, B.; JOYCE, R.; SHEPTAK, R.; HETHERINGTON, K.; CASTILLO, M.; IORIS, R. $21^{\text {st }}$ Century Golpismo: A NACLA Roundtable. NACLA Report on the Americas 46(4): 322-333, 2016

POSSAMAI, A. J. Portal Brasileiro de Dados Abertos: novas práticas para o fortalecimento da democracia e da gestão pública na Era Digital. In SILVA, S. P.; BRAGATTO, R. C.; SAMPAIO, R. C. (eds.). Democracia Digital, Comunicação Política e Redes: Teoria e Prática. Rio de Janeiro: Folio Digital, p. 365-392, 2016.

PRUDÊNCIO, K., RIZZOTTO, C. \& SILVA, M. Muita cena e pouca comunicação política? A Marcha das Vadias nos portais de notícias e a questão do reconhecimento. Estudos em Jornalismo e Mídia 13(1): 89-102, 2016.

RIZOTTO, C.; PRUDÊNCIO, K.; SAMPAIO, R. C. Tudo normal. A despolitização no enquadramento multimodal da cobertura do impeachment de Dilma Rousseff. Comunicação \& Sociedade 39(3): 111-130, 2017.

ROGERS, E. M. Communication and Development. The Passing of the Dominant Paradigm. Communication Research 3(2): 213-240, 1976.

ROGERS, E. M. The department of communication at Michigan state university as a seed institution for communication study, Communication Studies, 52(3): 234-248, 2001.

ROTHSTEIN, B. The Quality of Government. Corruption, Social Trust and Inequality in Comparative Perspective. Chicago: The University of Chicago Press, 2011.

SAMPAIO, R. C.; BRAGATTO, R.C.; NICOLÁS, M. A. A construção do campo de internet \& política. Análise dos artigos brasileiros apresentados entre 2000 e 2014. In SILVA, S. P.; BRAGATTO, R. C.; SAMPAIO, R. C. (eds.). Democracia Digital, Comunicação Política e Redes: Teoria e Prática. Rio de Janeiro: Folio Digital, p. 77-108, 2016. 
SAMPAIO, R.C, MAIA, R. C. M; MARQUES, F. P. J. A. Participação e deliberação na internet: um estudo de caso do Orçamento Participativo Digital de Belo Horizonte. Opinião Pública 16(2): 446-477, 2010.

SANTISO, C. Economic Reform and Judicial Governance in Brazil: Balancing Independence with Accountability. In GLOPPEN, S.; GARGARELLA, R.; SKAAR, E. Democratization and the Judiciary: The Accountability Function of Courts in New Democracies. London. Portland (OR): Frank Cass 117-131, 2004.

SANTOS, A. The World Bank's Uses of the "Rule of Law" Promise in Economic Development. In TRUBEK, D. M.; SANTOS, A. (ed.). The New Law and Economic Development: A Critical Appraisal. Cambridge: Cambridge University Press, 2006.

SANTOS, J. G. B.; ALDÉ, A. As manifestações de junho: estratégias em rede para a resistência civil In: Mendonça, R. F., Pereira, M. A., Filgueiras. F. (Org.). Democracia digital: publicidade, instituições e confronto político. Belo Horizonte: UFMG, p. 479-503, 2016.

SANTOS, M. A. Campanha não oficial - A Rede Antipetista na eleição de 2014. Fronteiras: Estudos Midiáticos 19(1): 102-119, 2016.

SANTOS, W.G. A democracia impedida: O Brasil no Século XXI. Rio de Janeiro: FGV Editora, 2017.

SAPIEZYNSKA, E.; LAGOS, C. Media Freedom Indexes in Democracies: A Critical Perspective through the Cases of Poland and Chile. International Journal of Communication 10: 549-570, 2016.

SARMENTO, R.; CHAGAS, V. Bela, recatada e do bar: memes de internet, política e gênero. Trabalho apresentado no VII Congresso da Compolítica, Porto Alegre, 2017.

SARMENTO, R.; MENDONÇA, R. F. As jornadas de junho e a questão de gênero: idas e vindas das lutas por justiça. Revista Brasileira de Ciência Política 22: 93-128, 2017.

SCHWARTZ, R. Ao vencedor, as batatas. São Paulo: Duas Cidades, 1977.

SEYBOLD, P. The Ford Foundation and the Transformation of Political Science. In SCHWARTZ, M. (ed). Structure of Power in America. New York: Holmes and Meier, p. 185-198, 1987.

SIEBERT, F. S.; PETERSON, T.; SCHRAMM, W. Four Theories of the Press. Chicago: Illinois University Press, 1963.

SILVEIRA, S. A. Ciberativismo, cultura hacker e o individualismo colaborativo. Revista USP 86: 28-39, 2010.

SLAUGHTER, S.; LESLIE, L. L. Expanding and Elaborating the Concept of Academic Capitalism. Organization 8(2): 154-161, 2001.

SPARKS, C. How coherent is the BRICS grouping? In Nordenstreng K, Thussu DK. (eds.) Mapping BRICS Media. London: Routledge, pp. 42-65, 2015.

STEIBEL, F. O portal da consulta pública do Marco Civil da internet. In LEITE, G. S.; LEMOS, R. (eds.). Marco Civil da Internet. São Paulo: Atlas, 2014. 
STEINER, N. D. Comparing Freedom House Democracy Scores to Alternative Indices and Testing for Political Bias: Are US Allies Rated as More Democratic by Freedom House? Journal of Comparative Policy Analysis: Research and Practice, 2014. doi:

10.1080/13876988.2013.877676

TRASEL, M. R. Hacks and hackers: the ethos and beliefs of Data-Driven Journalism professionals in Brazil. Revista Famecos 25(1). Ahead of the print, 2018

TSYGANKOV, AP and PARKER, D. The securitization of democracy: Freedom House ratings of Russia. European Security 24(1) 77-100, 2014.

VIANNA, L. W.; BURGOS, M; SALLES, P. Dezessete anos de judicialização da política. Tempo social. vol.19, n.2, pp. 39-85, 2007.

WALTERS, P. B.; BOWMAN, E. A. Foundations and the Making of the Public Education in the United States, 1867-1950. In ANHEIER, H. K.; HAMMACK, D. C. (eds.) American Foundations: Roles and Contributions. Washington, DC: Brookings Institution Press, pp. 31-50, 2010.

WIEDEMANN, T.; MEYEN, M. Internationalization through Americanization: The Expansion of the International Communication Association's Leadership to the World. International Journal of Communication 10: 1489-1509, 2016.

WILLIAMS, D.; Young, T. Governance, the World Bank and Liberal Theory. Political Studies 42(1): 84-100, 1994.

WILLIAMSON, J. A Short History of the Washington Consensus. In SERRA, N.; STIGLITZ, J. E. (eds). The Washington Consensus Reconsidered. Towards a New Global Governance. Oxford: Oxford University Press, 2008.

VAN DIJK, T. (2017). How Globo media manipulated the impeachment of Brazilian President Dilma Rousseff. Discourse \& Communication 11(2): 199-229.

\section{O autor}

Afonso Albuquerque é professor e pesquisador do programa de Pós-Graduação em Comunicação - Universidade Federal Fluminense. Doutor em Comunicação e Cultura Universidade Federal do Rio de Janeiro (1996). 